\title{
Association of Physical Fitness Indicators with Health Profile and Lifestyle of Children
}

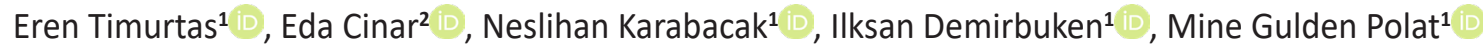 \\ ${ }^{1}$ Marmara University, Health Science Faculty, Department of Physiotherapy and Rehabilitation, Maltepe, Istanbul, Turkey \\ ${ }^{2}$ CRCHUS, Universite de Sherbroke, Sherbrooke, Quebec, Canada \\ Correspondence Author: Neslihan Karabacak \\ E-mail: neslikarabacak@gmail.com \\ Received: $31.07 .2020 \quad$ Accepted: 30.05 .2021
}

\begin{abstract}
Objective: High physical fitness (PF) level is a significant health determinant in children and adolescents so that it is important to identify the factors affecting PF in this population. Despite available studies highlighting the relationship between PF and characteristics of children, there is still a need to uncover how the health status and lifestyle of children impact different PF indicators. Thus, the purpose of this study is to investigate the relationship between physical fitness, and the health profile and lifestyle of children.

Methods: This study was conducted with 110 (58 girls; age 11.85 \pm 0.35 ) adolescents between February and March 2020. The preditors of PF which were gender, body mass index, physical activity level (PAL) measured via Physical Activity Questionnaire (PAQ), motivation measured via Participation Motivation Questionnaire (PMQ), sleep time, and tablet usage time regressed against PF related outcome measured using 6 Minutes Walk test (6MWT), T-Test, vertical jump test and broad jump test (BJT).

Results: There were significant associations between T-test performance, and gender, BMI (being obese), and PAL. PAL and gender were also significant predictors for 6MWT and BJT respectively. PF was not significantly associated with motivation, sleep, and table usage time. A high level of physical activity, being male, and low BMI score resulted in better PF performance.

Conclusion: The health profile and lifestyle of adolescents may estimate the significant proportion of variabilities observed in physical fitness levels in adolescents.
\end{abstract}

Keywords: Physical Fitness, Adolescent, Physical Activity, Healthy Lifestyle

\section{INTRODUCTION}

Physical Fitness (PF) is defined as a state of health associated with aerobic capacity, flexibility, muscular endurance, and muscular strength, which is linked to the ability to perform aspects of sports and outdoor recreational activities (1).

Improving physical fitness during adolescence is crucial to avoid the development of chronic disease in adulthood $(2,3)$ and to improve health-related quality of life $(4)$. It is an important factor leading to success in youth sports and athletic events $(5,6)$. Further, youth's academic achievement $(7,8)$, and participation in physical (9) and social activities (10) have also been linked to physical fitness.

Studies in the adult population emphasized the impact of biological and lifestyle factors on physical fitness (11). Sex, for example, is reported as an important determinant for physical activity level and participation in sports in adults; yet, the difference between sex was not conclusive in youth (12). Also, the relationship between body mass index (BMI) and fitness level has been largely documented in both adult (13) and adolescent populations [14] relating to the prevalence of obesity (15). Although several studies illustrated an inverse relationship between the BMI and physical fitness level (16), the trend was opposite in others (17).

One of the worrying findings is that sedentary lifestyle and inadequate physical activity are becoming more common in adolescents (18) which is carried into adulthood (19). Recent studies highlighted the use of electronic devices as the most important factor in this behavior $(20,21)$. It was shown that the use of electronic devices has significantly deteriorated the level of physical activity in adolescents $(22,23)$. Studies were done in Turkish adolescents also contributed evidence to this phenomenon; where they showed a significant association between the use of the mobile device and the reduced time invested for physical activity (24). A longitudinal study in England adolescents also showed that physical activity was affected inversely by the increase in screen time (25). Despite the recommendations from health agencies like World Health 
Organization (WHO) to reduce the time spent on the screen (26), the use of mobile devices is becoming more common in adolescents which in turn influences their physical fitness levels (25). Understanding the relationship between lifestyle factors, health profiles, and level of physical fitness is still a research area of interest to better design interventions for adolescents and prevent them from moving into unhealthy adulthood.

The purpose of this study is to estimate the extent to which physical fitness levels are associated with sex, BMI, physical activity, sedentary, tablet using, sleep time in healthy adolescents.

\section{METHODS}

\subsection{Participants}

Healthy adolescents aged between 9 to 14 years who are secondary grade schools in Istanbul participated in this study. The data was collected between February-March 2020 in two secondary grade schools in Istanbul. Those two schools were selected across Istanbul using a random sampling method.

A total of 110 adolescents (average age 11.85 $\pm 0.35 ; 47 \%$ male) with no diagnosis of neurological, cardiovascular, metabolic, rheumatic, or vestibular diseases, no injuries or previous surgery participated in the population-based crosssectional study.

Written informed consent from parents and assents from the adolescents were obtained before participating in this study. Assessments were conducted within the school hours as permitted by the school administration.

The study's ethical approval was obtained from Marmara Research Ethics Committee (No:178 Date: 05.12.2019).

\subsection{Measurements}

\subsubsection{Personal factors}

Age, sex, height, and weight were obtained using a standardized data collection form created by the researchers. Additionally, information on sleep times and tablet usage times were obtained.

\subsubsection{Physical fitness assessment}

The outcome of this study is Cardiorespiratory Fitness (CRF) which was measured using the 6 Minute Walk Test (6MWT) according to American Thoracic Society Guidelines (27). The distance walked within 6 minutes was measured.

\subsubsection{Physical Activity Level}

The activity level was obtained from the Physical Activity Questionnaire (PAQ). The PAQ includes 10 items that capture activities in and out of school during the last seven days. Except for the last question, each item scores on a 5 Likert scale and produces an activity score between 1-5. Score 1 implies low physical activity whereas a score of 5 implies high physical activity. The points given to the 9 questions are collected and the total score was obtained by dividing the number of questions. Psychometrics of PAQ for the Turkish version was conducted by Erdim at all (28).

\subsubsection{Motivation in Participating in Sports}

Participation Motivation Questionnaire (PMQ) consists of 30 items including the reasons for participation in sports. The PMQ has 8 dimensions which are skill development, team membership / spirit, entertainment, friend, achievement / status, physical fitness /energy spending, movement / being active, and contest. It is scored on a 3 Likert scale. (1 very important, 2 less important, 3 not important). Psychometrics of PAQ for the Turkish version was conducted in 9-17 aged group students by Oyar at all (29).

\subsubsection{Agility}

Agility is measured using the T-test. The completion time of the 4-cones course at a certain distance is recorded. T-Test was applied according to Semenick's Test Protocols (30). The assessment was repeated only one time.

\subsubsection{Vertical Jump and Broad Jump Test}

Vertical and Broad Jump tests were used to measure the lower limb muscle strength (31). The Eurofit test battery was applied for the test procedure. In the Vertical jump test, the person jumps vertically with support from the knees. The distance between the endpoint the person reaches and the starting point is measured. Standing Broad Jump Test is measured on a non-slip floor, double foot jumping as far as possible. The distance between the starting point and the heel after landing is measured. Two attempts were allowed in both tests. The vertical jump test is a variation of the Broad Jump Test (32).

\subsection{Analysis}

Descriptive statistics were used to summarize the demographic information of the participants and all performance scores. The distributions of the data were visually evaluated by histograms, and Quantile-Quantile plots; and tested using the Shapiro-Wilk test. Before the main analysis, the collinearity among independent variables was examined using Variance Inflation Factor (VIF) and regression correlation matrix for Klein Goldberger model. The outcomes of interest, 6MWT, T-test, vertical jump test, and broad jump test, were regressed against six independent variables: sex, $\mathrm{BMI}$ percentile, sleep time, tablet usage time, $\mathrm{PMQ}$, and $\mathrm{PAQ}$. The categorical variables (sex and BMI percentile) were included in the regression models. Reference categories for was normal level for BMI ( $>5$ and $<85$ th percentile) and 
female for sex. The model was visually evaluated for linearity, heteroscedasticity, and normality of the residuals. The alpha level was set .05. All analyses were done is R statistical software using the packages of 'olsrr'and 'lubridate' (Version 3.6.0, St .Louis, Missouri, USA) (33).

\section{RESULTS}

Table 1 summarizes the demographic and characteristics of participants including age, gender, BMIz, sleeping time, tablet usage time, participation motivation questionnaire, physical activity questionnaire, 6MWT, T-test score, vertical jump test, and broad jump test.

Table 1. Baseline characteristics and predictors

\begin{tabular}{|l|l|l|}
\hline Variables (n) & Mean (SD) & N (\%) \\
\hline Age & $11.85(0.35)$ & \\
\hline Gender & & \\
\hline Female & - & $58(53)$ \\
\hline Male & - & $52(47)$ \\
\hline BMI WHO classification & & \\
\hline BMI percentile <5:Underweight & & $4(4)$ \\
\hline BMI percentile $\geq 5$ and <85:Healthy Weight & & $65(59)$ \\
\hline BMI percentile $\geq 85$ and <95:Overweight & & $26(24)$ \\
\hline BMI percentile $\geq 95:$ Obese & & $14(13)$ \\
\hline BMlz score & $0.19(0.03)$ & $134(100)$ \\
\hline Life-style and activity & & \\
\hline Sleeping time (m) & $528.12(77.32)$ & $90(100)$ \\
\hline Table usage time & $128.79(102.69)$ & $90(100)$ \\
\hline PMQ & $40.87(6.70)$ & $90(100)$ \\
\hline PAQ & $2.83(0.68)$ & $134(100)$ \\
\hline Physical fitness & & $134(100)$ \\
\hline $6 M W T$ (m) & $541.59(58.42)$ & $134(100)$ \\
\hline T-test (s) & $16.42(2.58)$ & \\
\hline Broad jump (cm) & $124.63(25.68)$ & $134(100)$ \\
\hline Vertical jump(cm) & $25.64(4.43)$ & $134(100)$ \\
\hline BMI: Body Mass $)$ & & \\
\hline
\end{tabular}

BMI: Body Mass Index, PMQ: Participation Motivation Questionnaire, PAQ: Physical Activity Questionnaire, 6MWT: 6 Minutes Walk Test. SD: Standard deviation

\section{Multiple regression analysis}

The result of multiple regression analyses is presented in Table 2. The correlation coefficients between predictors were tolerable $(r<0.5)$ (34). The predictors included in the analysis explained $16-41 \%$ of the variation in physical fitness indicators (Table 2). The analyses showed that only three of the predictors-gender and BMI and PA - had significant relationships with physical fitness indicators (Table 2). Being female was associated with increased time in the T-test and shorter distance in BJT (Table 2). Being obese was also significantly related to a longer time in the T-test. On the other hand, having a higher PAQ score was significantly associated with a shorter time in the T-test and higher distance in 6MWT. There were no significant relationships between physical fitness indicators and three predictors (motivation, sleep, and table usage time) (Table 2).
Table 2. Multiple regression analysis: relationship between each predictor and physical fitness indicators

\begin{tabular}{|c|c|c|c|c|c|c|c|c|}
\hline \multicolumn{9}{|c|}{ OUTCOMES (PHYSICAL FITNESS INDICATORS) } \\
\hline & \multicolumn{2}{|c|}{6 MWT score } & \multicolumn{2}{|c|}{ T test score } & \multicolumn{2}{|c|}{ VJT score } & \multicolumn{2}{|c|}{ BJT score } \\
\hline $\begin{array}{l}\text { PREDICTORS } \\
\text { (range) }\end{array}$ & B & $p$ & B & $p$ & b & $p$ & B & $p$ \\
\hline $\begin{array}{l}\text { Gender } \\
\text { (female) }\end{array}$ & 4.438 & 0.715 & 1.24 & 0.007 & -1.029 & 0.292 & -12.44 & 0.018 \\
\hline \multicolumn{9}{|l|}{ BMIz } \\
\hline $\begin{array}{l}\text { Underweight } \\
<5^{\text {th }} \text { percentile }\end{array}$ & -8.125 & 0.786 & 0.946 & 0.367 & -1.171 & 0.626 & 6.457 & 0.613 \\
\hline $\begin{array}{l}\text { Overweight } \\
>85 \text { and }<95^{\text {th }}\end{array}$ & -26.15 & 0.401 & 1.432 & 0.217 & -2.593 & 0.299 & -4.509 & 0.733 \\
\hline Obesity & -59.48 & 0.090 & 4.423 & 0.001 & -4.41 & 0.115 & 0.285 & 0.285 \\
\hline $\begin{array}{l}\text { Sleep time } \\
(360,840)\end{array}$ & -23.09 & 0.552 & 0.701 & 0.625 & -0.755 & 0.806 & -3.98 & 0.808 \\
\hline $\begin{array}{l}\text { Table usage } \\
\text { time } \\
(0,600)\end{array}$ & 13.78 & 0.06 & -0.304 & 0.264 & -0.381 & 0.515 & -4.504 & 0.149 \\
\hline $\begin{array}{l}\text { PMQ } \\
(30,57)\end{array}$ & -46.60 & 0.22 & 2.681 & 0.064 & -5.016 & 0.107 & -26.62 & 0.107 \\
\hline $\begin{array}{l}\text { PAQ } \\
(1.31,4.41)\end{array}$ & 98.52 & 0.002 & -4.647 & 0.001 & 4.24 & 0.109 & 25.79 & 0.066 \\
\hline$R^{2}$ & \multicolumn{2}{|c|}{0.20} & \multicolumn{2}{|c|}{0.41} & \multicolumn{2}{|c|}{0.16} & \multicolumn{2}{|c|}{0.28} \\
\hline
\end{tabular}

BMI: Body Mass Index, PMQ: Participation Motivation Questionnaire, PAQ: Physical Activity Questionnaire.

\section{DISCUSSION}

This study aimed to show the relationship between physical fitness indicators and characteristics and lifestyle of adolescents aged 11-12 years. Based on the results, the health profile and lifestyle of adolescents may estimate the significant proportion of variabilities observed in physical fitness level in adolescents that was ranged from 16 to $41 \%$. Being female and being obese were significantly associated with a low fitness level while a high level of participation in physical activity was a significant indicator of better fitness. On the other hand, the motivation and time spending on sleep and table usage were not significantly related to the physical fitness level of the participants.

Physical fitness is a significant health marker of adolescents that predict their aerobic and anaerobic capacities allowing us to estimate the risk of cardiac and health problems in adulthood, participation in social and physical activities, academic performance, and psychosocial problems. This study adopted 6MWT to measure the aerobic capacity and endurance rather than direct measures of VO2 max expenditure to reflect adolescents' ability to perform daily activities. Where VO2 max was measured, boys were consistently reported to have a higher level of VO2 max capacities than girls (35). Though, the gender differences in 6MWT were not as conclusive in the literature $(36,37)$. The current study reported no differences in distance covered within six minutes between gender which was inconsistent with the previous study done in a similar population, Turkish children and adolescents, where Kanburoglu et al presented outstanding performance of boys compared to girls (38). Comparable performance between gender in the current 
study may be a result of unmatched characteristics between girls and boys in the lifestyle or physical activity level of the participants. Kanburoglu et al compared the performance of girls and boys after separating the participants with respect to physical activity (PA) level as sedentary, active, and very active (38). The group differences were evidence in each PA level where boys covered a greater distance than girls. On the other hand, compatible with the current study, they found no differences among the adolescents with different levels of $\mathrm{BMI}$ in 6MWT. Indeed, 6MWT is presented as a valid test that can distinguish obese adolescents from those with normal weight (39) which was not the case in Turkish adolescents (38). In regard to oxygen uptake, obese adolescents typically presented with higher or relatively comparable oxygen consumption level with those with normal weight (40) which may be a factor leading to a comparable performance in 6MWT considering the nature of the test measuring aerobic capacity and endurance.

This study also showed that the fitness levels of Turkish adolescents highly vary dependent on the amount of time they invest in physical activity. A negative relationship between a sedentary lifestyle and physical fitness has been consistently shown in adolescents with varying age groups. Carson et al, for example, showed poorer cardiorespiratory capacity and endurance in adolescents who spent time on screen more than their peers (21). Nevertheless, the results of our study did not provide supportive evidence; on the contrary, the table usage time and sleep time were not significantly associated with physical fitness level through physical activity time was.

Increased screen time has also negatively affected the locomotor skills and muscular strength of adolescents in some studies $(25,41)$. Despite these strong evidences, a recent meta-analysis reported no significant relationship between sedentary time and physical fitness level in either boys or girls (42). Studies suggest lifestyle with sports participants contributor for PA levels (42). Higher PA habitual benefit for cardiorespiratory and agility strength as an important healthy biomarker (43). Participants who have higher PA levels show greater performance in the T-test as agility test and 6MWT as cardiorespiratory capacity. These results were similar to current studies which provide an association between PA, sedentary behaviors, and physical fitness (4). The evidence indicates meeting the recommended PA level contributes to spending less time $(44,45)$.

Although evidence emphasized that PA and sedentary time different dimensions of lifestyle $(46,47)$. There are inconsistent results in the studies. Studies found that children who spent time on the screen, they less active. On the other hand, these studies found that active adolescents spend a lot of time on screen (48).

Telama at all. suggested that PA habitual tends to PA in adulthood in their 21 tracking study (49). PA represents any physical movement produced by skeletal muscles, it improves physical fitness status (50).
There was no available evidence for Turkish adolescents to show the relationship between physical fitness and lifestyle. This study provides to determine the effect of gender, BMI, physical activity, sedentary, tablet using, sleep time on the physical fitness levels in Turkish adolescents. The predictors included that three of the predictors-gender and BMI and PA - had significant relationships with physical fitness indicators. Obesity was also significantly related to a longer time in the T-test. On the other hand, PA was significantly associated with a shorter time in the T-test and higher distance in 6MWT.

Future studies may also investigate the effect of lifestyle intervention on physical fitness levels in adolescents.

\section{CONCLUSION}

The results of the current study present that the health profile and lifestyle parameters may contribute to physical fitness such as cardiorespiratory fitness and agility in Turkish adolescents. In conclusion, lifestyle management and obesity should be a major focus in public health.

\section{REFERENCES}

[1] Pescatello LS, D Riebe, And PD Thompson. ACSM's Guidelines for Exercise Testing and Prescription. Lippincott Williams \& Wilkins 2014.

[2] Must A, Strauss RS. Risks and Consequences of Childhood And Adolescent Obesity. International Journal of Obesity 1999; 23(2): P. S2-S11.

[3] Gunnell DJ, Frankel SJ, Nanchahal K, Peters TJ, Davey Smith G. Childhood Obesity and Adult Cardiovascular Mortality: A 57-Y Follow-Up Study Based on The Boyd Orr Cohort. The American Journal of Clinical Nutrition 1998;67(6), 1111-1118.

[4] Bermejo-Cantarero A, Alvarez-Bueno C, Martinez-Vizcaino V, Garcia-Hermoso A, Torres-Costoso A I, Sanchez-Lopez M. Association Between Physical Activity, Sedentary Behavior, And Fitness With Health Related Quality Of Life In Healthy Children And Adolescents: A Protocol For A Systematic Review And Meta-Analysis. Medicine 2017; 96(12).

[5] Huang HC, Wu WL, Chang YK, Chu IH. Physical Fitness Characteristics of Adolescent Wushu Athletes. The Journal of Sports Medicine and Physical Fitness 2016; 58(4), 399-406.

[6] Cattuzzo MT, Dos Santos Henrique R, Ré AHN, De Oliveira IS, Melo BM, De Sousa Moura M, De Araújoc RC, Stodden D. Motor Competence and Health Related Physical Fitness In Youth: A Systematic Review. Journal of Science and Medicine in Sport 2014; 19(2), 123-129.

[7] Santana CCA, Azevedo LB, Cattuzzo MT, Hill JO, Andrade LP, Prado WL. Physical Fitness and Academic Performance in Youth: A Systematic Review. Scandinavian Journal of Medicine \& Science in Sports 2017; 27(6), 579-603.

[8] Ortega FB, Ruiz JR, Castillo MJ, Sjöström M. Physical Fitness in Childhood and Adolescence: A Powerful Marker of Health. International Journal of Obesity 2008; 32(1): P. 1-11.

[9] Rauner A, Mess F, Woll A. The Relationship Between Physical Activity, Physical Fitness And Overweight In Adolescents: A Systematic Review of Studies Published in or After 2000. BMC Pediatrics, 2013; 13(1): P. 19. 
[10] Smith AL. Peer Relationships In Physical Activity Contexts: A Road Less Traveled In Youth Sport And Exercise Psychology Research. Psychology of Sport And Exercise, 2003; 4(1): P. 2539.

[11] Twisk J, Kemper H, Van Mechelen W. The Relationship Between Physical Fitness and Physical Activity During Adolescence and Cardiovascular Disease Risk Factors At Adult Age. The Amsterdam Growth and Health Longitudinal Study. Int J Sports Med 2002; 23(S1), 8-14.

[12] Dencker M, Andersen LB, Accelerometer-Measured Daily Physical Activity Related to Aerobic Fitness in Children and Adolescents. Journal of Sports Sciences 2011; 29(9): P. 887895.

[13] Kim JH, So WY. Associations Between Overweight/Obesity and Physical Fitness Variables In Korean Women. Cent Eur J Public Health 2013; 21(3), 155-159.

[14] Koulouvaris P, Tsolakis C, Tsekouras YE, Donti O, Papagelopoulos PJ. Obesity and Physical Fitness Indices of Children Aged 5-12 Years Living on Remote and Isolated Islands. Rural Remote Health 2018; 18(2), 4425.

[15] Foley S, Quinn S, Dwyer T, Venn A, Jones G. Measures Of Childhood Fitness and Body Mass Index Are Associated With Bone Mass In Adulthood: A 20-Year Prospective Study. Journal of Bone and Mineral Research 2008; 23(7), 994-1001.

[16] So WY, Choi DH, Differences In Physical Fitness And Cardiovascular Function Depend On BMI In Korean Men. Journal of Sports Science \& Medicine 2010; 9(2): P. 239.

[17] Lopes VP, Malina RM, Gomez-Campos R, Cossio-Bolaños M, De Arruda M, Hobold E.Body Mass Index and Physical Fitness in Brazilian Adolescents. Jornal De Pediatria (Versão Em Português) 2019; 95(3): P. 358-365.

[18] Chen X, Sekine M, Hamanishi S, Wang H, Gaina A, Yamagami T, Kagamimori S. Lifestyles And Health-Related Quality of Life in Japanese School Children: A Cross-Sectional Study. Preventive Medicine 2005; 40(6): P. 668-678.

[19] Tammelin T, Näyhä S, Laitinen J, Rintamäki H, Järvelin MR. Physical Activity And Social Status in Adolescence As Predictors of Physical Inactivity In Adulthood. Preventive Medicine 2003; 37(4), 375-381.

[20] Tremblay MS, Leblanc AG, Kho ME, Saunders TJ, Larouche R, Colley RC, Goldfield Gary, Gorber SC. Systematic Review Of Sedentary Behaviour And Health Indicators in SchoolAged Children and Youth. International Journal of Behavioral Nutrition and Physical Activity 2011. 8(1): P. 98.

[21] Carson V, Hunter S, Kuzik N, Gray CE, Poitras VJ, Chaput JP, Saunders TJ, Katzmarzyk PT, Okely AD, Gorber S, Kho ME, Sampson M, Lee H, Tremblay MS. Systematic Review of Sedentary Behaviour and Health Indicators in School-Aged Children and Youth: An Update. Applied Physiology, Nutrition, and Metabolism 2016; 41(6): P. S240-S265.

[22] Sandercock GR, Ogunleye A, Voss C. Screen Time and Physical Activity In Youth: Thief Of Time Or Lifestyle Choice? Journal of Physical Activity and Health 2012; 9(7), 977-984.

[23] Ogunleye AA, Voss C, Sandercock GR. Prevalence of High Screen Time in English Youth: Association with Deprivation and Physical Activity. Journal of Public Health 2012; 34(1): P. 46-53.

[24] Kin-Isler A, Asci F, Altintas A, Guven-Karahan B. Physical Activity Levels and Patterns of 11-14 Year-Old Turkish Adolescents. Adolescence 2009; 44(176).
[25] Aggio D, Ogunleye AA, Voss C, Sandercock GRH. Temporal Relationships Between Screen-Time and Physical Activity with Cardiorespiratory Fitness in English Schoolchildren: A 2-Year Longitudinal Study. Preventive Medicine 2012; 55(1): P. 37-39.

[26] lannotti RJ, Janssen I, Haug E, Kololo H, Annaheim B, Borraccino A. Interrelationships of Adolescent Physical Activity, ScreenBased Sedentary Behaviour, and Social and Psychological Health. International Journal of Public Health 2009; 54(2): 191-198.

[27] ATS Committee on Proficiency Standards for Clinical Pulmonary Function Laboratories. ATS statement: guidelines for the sixminute walk test. Am J Respir Crit Care Med, 166 (1): 111-117.

[28] Erdim L, Ergun A, Kuguoglu S. 71 Reliability and Validity of Turkish Version of The Physical Activity Questionnaire for Older Children (PAQ-C). Arch Dis Child 2012; 97(Suppl 2), A20-A20.

[29] Oyar ZB, Aşçı FH, Çelebi M, Mülazlmoğlu Ö. "Spora Katııım Güdüsü Ölçeği”nin Geçerlik ve Güvenirlik Çalışması. Spor Bilimleri Dergisi 2001; 12(2), 21-32.

[30] Semenick D. Tests and Measurements: The T-Test. Strength \& Conditioning Journal 1990; 12(1), 36-37.

[31] Castro-Piñero J, González-Montesinos JL, Mora J, Keating XD, Girela-Rejón MJ, Sjöström M, Ruiz JR. Percentile Values for Muscular Strength Field Tests in Children Aged 6 to 17 Years: Influence of Weight Status. The Journal of Strength \& Conditioning Research 2009; 23(8), 2295-2310.

[32] Andrade S, Lachat C, Ochoa-Aviles A, Verstraeten R, Huybregts L, Roberfroid D, Andrade D, Camp JV, Rojas R, Donoso S, Cardon G, Kolsteren P. A School-Based Intervention Improves Physical Fitness in Ecuadorian Adolescents: A Cluster-Randomized Controlled Trial. International Journal of Behavioral Nutrition and Physical Activity 2014; 11(1), 153.

[33] Team, RCR. A Language and Environment for Statistical Computing. R Foundation for Statistical Computing; 2013.

[34] Dormann CF, Elith J,Bacher S,Buchmann C, Carl G, Carré G, Marquez JRG, Gruber B, Lafourcade Bruno, Leitao P, Münkemüller $T$, Mcclean $C$, Osborne $P E$, Reineking Björn, Schröder B, Skidmore AK, Zurell D, Lautenbach S. Collinearity: A Review of Methods to Deal with It and A Simulation Study Evaluating Their Performance. Ecography 2013; 36(1): P. 2746.

[35] Olds T, Tomkinson G, Léger L, Cazorla G. Worldwide Variation in The Performance of Children and Adolescents: An Analysis of 109 Studies of the 20-M Shuttle Run Test In 37 Countries. Journal of Sports Sciences 2006; 24(10), 1025-1038.

[36] Lammers AE, Hislop AA, Flynn Y, Haworth SG. The 6-Minute Walk Test: Normal Values for Children of 4-11 Years Of Age. Arch Dis Child 2008; 93(6), 464-468.

[37] Li AM, Yin J, Au JT, So HK, Tsang T, Wong E, Fok TF, Ng PC. Standard Reference For The Six-Minute-Walk Test In Healthy Children Aged 7 To 16 Years. Am J Respir Crit Care Med 2007; 176(2), 174-180.

[38] Kanburoglu MK, Ozdemir FM, Ozkan S, Tunaoglu FS. Reference Values of The 6-Minute Walk Test In Healthy Turkish Children And Adolescents Between 11 And 18 Years Of Age. Respir Care 2014; 59(9), 1369-1375.

[39] Morinder G, Mattsson E, Sollander C, Marcus C, Larsson UE. Six-Minute Walk Test in Obese Children and Adolescents: Reproducibility and Validity. Physiotherapy Research International: The Journal for Researchers and Clinicians in Physical Therapy 2009; 14(2), 91-104. 
[40] Harris KC, Al Saloos HA, De Souza AM, Sanatani S, Hinchliffe M, Potts JE, Sandor GGS. Biophysical Properties of The Aorta and Left Ventricle and Exercise Capacity In Obese Children. The American Journal of Cardiology 2012; 110(6), 897-901.

[41] Hardy LL, Ding D, Peralta LR, Mihrshahi S, Merom D. Association Between Sitting, Screen Time, Fitness Domains, And Fundamental Motor Skills In Children Aged 5-16 Years: Cross-Sectional Population Study. Journal of Physical Activity and Health 2018; 15(12), 933-940.

[42] Van Ekris E, Altenburg T, Singh AS, Proper KI, Heymans MW, Chinapaw MJ. An Evidence-Update on The Prospective Relationship Between Childhood Sedentary Behaviour And Biomedical Health Indicators: A Systematic Review and MetaAnalysis. Obesity Reviews 2016; 17(9), 833-849.

[43] Lang JJ, Larouche R, Tremblay MS. The Association Between Physical Fitness And Health In A Nationally Representative Sample Of Canadian Children And Youth Aged 6 To 17 Years. Maladies Chroniques Et Blessures Au Canada 2019; 39(3).

[44] Morrow JR, James R, Tucker JS, Jackson AW, Martin SB, Greenleaf CA, Petrie TA. Meeting Physical Activity Guidelines and Health-Related Fitness in Youth. Am J Prev Med 2013; 44(5), 439-444.
[45] Tucker JS, Martin S, Jackson AW, Morrow JR, Greenleaf CA, Petrie TA. Relations Between Sedentary Behavior and FITNESSGRAM Healthy Fitness Zone Achievement and Physical Activity. Journal of Physical Activity and Health 2014; 11(5), 1006-1011.

[46] Samdal O, Tynjälä J, Roberts C, Sallis JF, Villberg J, Wold B. Trends in Vigorous Physical Activity and TV Watching of Adolescents From 1986 To 2002 In Seven European Countries. The European Journal of Public Health 2007; 17(3), 242-248.

[47] Taveras EM, Field AE, Berkey CS, Rifas-Shiman SL, Frazier AL, Colditz GA, Gillman MW. Longitudinal Relationship Between Television Viewing and Leisure-Time Physical Activity During Adolescence. Pediatrics 2007; 119(2), E314-E319.

[48] Telama R, Nupponen H, Piéron M. Physical Activity Among Young People in The Context of Lifestyle. European Physical Education Review 2005; 11(2), 115-137.

[49] Telama R, Yang X, Viikari J, Välimäki I, Wanne O, Raitakari O. Physical Activity From Childhood To Adulthood: A 21-Year Tracking Study. Am J Prev Med 2005; 28(3), 267-273.

[50] Malina RM, Bouchard C, Bar-Or O. Growth, Maturation, And Physical Activity: Human Kinetics.2004.

How to cite this article: Timurtas E, CInar E, Karabacak N, Demirbuken I, Polat MG. Association of Physical Fitness Indicators with Health Profile and Lifestyle of Children. Clin Exp Health Sci 2021; 11: 263-268. DOI: 10.33808/ clinexphealthsci.776067 